\title{
Effect of $\alpha_{1}$ - and $\alpha_{2}$-Adrenoceptor Agonists and Antagonists on ACTH Secretion in Intact and in Hypothalamic Deafferentated Rats
}

\author{
Kuniko SHIMIZU \\ Division of Bio-Function Research, Biomedical Research Laboratories. \\ Jikei University School of Medicine. Minato-ku, Tokyo 105. Japan
}

Accepted May 28, 1984

\begin{abstract}
The effect of systemically injected $\alpha_{1}$ - and $\alpha_{2}$-adrenoceptor agonists and antagonists on $\mathrm{ACTH}$ secretion was studied in rats. Epinephrine, norepinephrine, phenylephrine, clonidine, B-HT933, and B-HT920 caused a significant and dose-related increase of the ACTH concentration in the serum. The order of median effective dose (ED50) of these drugs on ACTH secretion was as follows: epinephrine : norepinephrine $<\mathrm{B}-\mathrm{HT} 920<$ clonidine $<$ phenylephrine $\ll$ B-HT933. Isoproterenol, a $\beta$-adrenoceptor agonist, had no effect on ACTH secretion. ACTH secretion induced by epinephrine or phenylephrine was significantly inhibited by $\alpha$-adrenoceptor antagonists, phentolamine and phenoxybenzamine. However, propranolol, a $\beta$-adrenoceptor antagonist, had no effect on ACTH secretion induced by epinephrine. Prazosin, an $\alpha_{1}$-antagonist, and yohimbine, an $\alpha_{2}$-antagonist, significantly blocked ACTH secretion induced by phenylephrine, an $\alpha_{1}$-agonist, and B-HT933, an $\alpha_{2}$-agonist, respectively. ACTH secretion induced by norepinephrine or a low dose of clonidine was inhibited by both prazosin and yohimbine. However. ACTH secretion induced by a high dose of clonidine was blocked only by prazosin. In rats with complete deafferentation of the medial basal hypothalamus ( $M B H)$, ACTH secretion induced by epinephrine, norepinephrine, and clonidine was significantly blocked, as compared with intact rats. These results suggest that both peripheral $\alpha_{1}$ - and $\alpha_{2}$-adrenoceptors are involved in ACTH secretion induced by systemically injected adrenergic drugs in rats, and intact neural pathways entering the $\mathrm{MBH}$ are necessary for this $\mathrm{ACTH}$ releasing action.
\end{abstract}

Epinephrine activates the pituitary-adrenal system and causes release of adrenocorticotropic hormone (ACTH) in animals (1-5) and in man (6). Since this effect is blocked by $\alpha$-adrenoceptor antagonists, the epinephrine induced ACTH secretion is considered to be mediated by $\alpha$-adrenoceptors (7-9). However, some investigators have shown the involvement of a $\beta$-adrenoceptor mechanism in the control of the pituitary-adrenal system (10, 11). Recently, $\alpha$-adrenoceptors have been subclassified into $\alpha_{1}$ - and $\alpha_{2}$-types according to the relative potencies and affinities of agonists and antagonists (12. 13). The first aim of this study is to confirm that $\alpha$-adrenoceptors are involved in ACTH secretion and furthermore, to investigate which of the two $\alpha$-adrenoceptors $\left(\alpha_{1}\right.$ and $\alpha_{2}$ ) is mainly responsible for ACTH secretion in rats. Prazosin and yohimbine were used as selective $\alpha_{1}$ - and $\alpha_{2}$-adrenoceptor antagonists, respectively, and the azepine derivatives B-HT933 (azepexole) and B-HT920, which are new experimental antihypertensive compounds, were used as highly selective $\alpha_{2}$ adrenoceptor agonists (14-18).

The medial basal hypothalamus $(\mathrm{MBH})$ is well known to be essential for regulation of ACTH secretion. Some stressful stimuli stimulate ACTH release by neural pathways entering the $\mathrm{MBH}$, while others stimulate it even after the deafferentation of the $\mathrm{MBH}$ $(19-23)$. The second aim of this study is to investigate whether or not the intact neural pathways into the $\mathrm{MBH}$ is necessary for ACTH secretion induced by systemic in- 
jection of adrenergic stimulating drugs. For this purpose, complete hypothalamic deafferentation around the $\mathrm{MBH}$ was performed using a Halász-type knife in rats.

\section{Materials and Methods}

Animals: Adult male rats of the Donryu strain weighing about $200 \mathrm{~g}$ were kept in an air-conditioned room (temperature $24 \pm 1^{\circ} \mathrm{C}$, $55 \pm 5 \%$ humidity) with a controlled lightdark cycle (lights on at 6:30 a.m. and lights off at 6:30 p.m.). Food (CE-2 cubic diet, Nihon Clea Co., Tokyo) and water were given ad libitum.

Hypothalamic deafferentation: Hypothalamic deafferentation was performed according to the method of Halász and Pupp (24), with minor modifications. Deafferentation was made in a stereotaxic instrument under pentobarbital anesthesia $(35 \mathrm{mg} / \mathrm{kg}$ i.p.) using a Halász-type knife with a $2.0 \mathrm{~mm}$ height and $1.7 \mathrm{~mm}$ radius. Complete cuts were made around the $\mathrm{MBH}$ : rostrally the knife was turned near the posterior edge of the optic chiasm, caudally in front of the mammillary body (Fig. 1). In the shamoperated rats, the knife was lowered into the brain to a ventral surface of the hypothalamus, without moving or turning it any further. The rats operated on were housed in individual cages. Experiments were done 5 to 6 days after the operation. Completeness of the hypothalamic cuts was ascertained histologically in each case. The brains were fixed in $10 \%$ formaldehyde, embedded in paraffin. cut into serial sections (10 /m thickness) and stained with hematoxylineosin.

Drugs: The following drugs were used: (1) agonists: epinephrine $\mathrm{HCl}$ (Bosmin, Daiichi), dl-norepinephrine $\mathrm{HCl}$ (Noradrenalin, Sankyo), phenylephrine $\mathrm{HCl}$ (NeoSynesin, Kowa), I-isoproterenol $\mathrm{HCl}$ (Proternol-1, Nitsuken Chemical), clonidine $\mathrm{HCl}$ (Tokyo Kasei), B-HT933 (Azepexole, 2amino-6 -ethyl-5,6,7,8-tetrahydro- $4 \mathrm{H}$ -

oxazolo-(4,5-d)-azepine. $2 \mathrm{HCl}$ ) (Nippon Boehringer Ingelheim. Thomae), B-HT920 (2-amino-6-allyl-5,6,7,8-tetrahydro-4H-

thiazolo-(4,5-d)-azepine, 2HCl) (Nippon Boehringer ingelheim. Thomae) and (2) antagonists: phentolamine mesylate (Regitine Ciba), phenoxybenzamine $\mathrm{HCl}$ (Dibenzyline, Tokyo Kasei), propranolol $\mathrm{HCl}$ (Inderal, Sumitomo Chemical), prazosin $\mathrm{HCl}$ (Pfizer Taito), yohimbine $\mathrm{HCl}$ (Nakarai Chemical). Drug solutions for injection were freshly prepared before each experiment. They were diluted with saline, except for phenoxybenzamine, prazosin, and yohimbine. Phenoxybenzamine was dissolved in propylene glycol-saline $(4: 3, v / v)$ solution and diluted with the same vehicle. Prazosin was emulsified in 1\% tween $80.49 \%$ paraffin liquid and $50 \%$ saline, and diluted with the same emulsified vehicle. Yohimbine was dissolved in distilled water and diluted with saline.

General procedures: Drugs were injected intraperitoneally (i.p.), except for prazosin which was injected subcutaneously (s.c.). The injection volume was $0.2 \mathrm{ml}$ per $100 \mathrm{~g}$ body weight. Control animals were injected
(A)

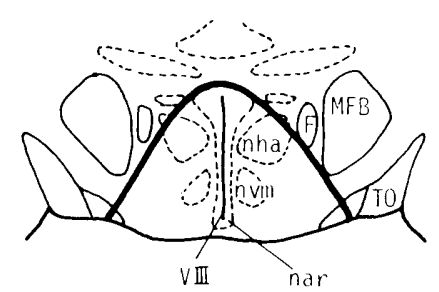

(i)

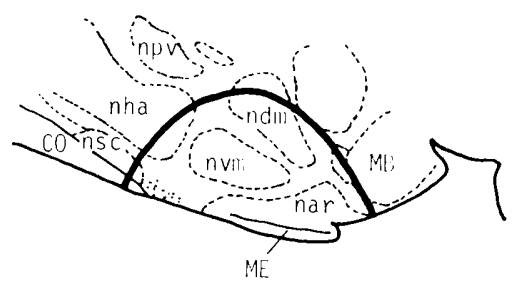

Fig. 1. Schematic drawings of the frontal (A) and sagittal (B) planes of the medial hypothalamus after complete hypothalamic deafferentation. Abbreviations: CO. optic chiasm: F, fornix; MB, mammillary body: ME, median eminence; MFB, medial forebrain bundle; TO, optic tract; nar, arcuate nucleus; ndm. dorsomedial nucleus: nsc, suprachiasmatic nucleus; nha, anterior hypothalamic nucleus: npv. paraventricular nucleus : nvm ventromedial nucleus. 
with an equal volume of saline or the vehicle. Rats were pretreated with antagonists and were killed by decapitation $10 \mathrm{~min}$ after the injection of agonists. The decapitation time was arranged from 9:00 to 11:00 a.m. in all the experiments. The trunk blood was collected into a plastic tube and rapidly cooled in ice-water. The serum was separated by centrifugation at $4^{\circ} \mathrm{C}$. ACTH in the serum was adsorbed to QUSO G32 (Philadelphia Quartz Co.). QUSO powder was washed with deionized-distilled water, and ACTH was extracted with $40 \%$ acetone in $1 \%$ acetic acid. The extract was evaporated to dryness in a vacuum centrifuge at $45^{\circ} \mathrm{C}$. As a standard for determining $\mathrm{ACTH}$ in the serum, synthetic $\mathrm{ACTH}_{1-24}$ (Cortrosyn, N.V. Organon) was added into $\mathrm{ACTH}$-free rat serum. The standard $\mathrm{ACTH} \mathrm{H}_{1-24}$ was treated by the same method that was used for the samples as described above. The details of these methods can be seen in a previous paper (25). The dried sample and the dried standard $\mathrm{ACTH}_{1-24}$ were stored at $-20^{\circ} \mathrm{C}$ until the $\mathrm{ACTH}$ bioassay.

Preparation of isolated rat adrenal cell suspension: Isolated rat adrenal cell suspension was prepared by the method of Sayers et al. (26) with the following modification: Decapsulated rat adrenal glands were cut into small pieces and put into trypsin solution which contained $0.25 \%$ trypsin $(1: 250$. Difco Laboratories) and 0.3\% bovine serum albumin (BSA) (Fraction $V$ from bovine plasma. Armour Pharmaceutical Co.) in $\mathrm{Ca}^{2+}$-free Krebs-Ringer-bicarbonate buffer containing $0.2 \%$ glucose (KRB-G). KRB-G was freshly prepared and saturated

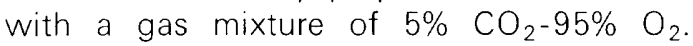
Trypsin digestion was carried out with gentle stirring at $35^{\circ} \mathrm{C}$ for $10 \mathrm{~min}$ for each step. The first fluid which contained the broken cells was discarded. A fresh trypsin solution was added to the residual adrenal tissues, and the trypsin digestion was continued for $10 \mathrm{~min}$. The fluid containing the isolated cells was filtered through an 80-mesh platinum sieve and pooled in an ice-cold flask. This procedure was repeated several times until the tissues were digested by trypsin completely. The pooled fluid was centrifuged at 700 r.p.m. for $10 \mathrm{~min}$ at $4^{\circ} \mathrm{C}$. After centrifugation, the precipitated cells were suspended in $5 \mathrm{ml}$ of KRB-G (2.54 mM Ca ${ }^{2+}$ ) containing $0.2 \%$ soybean trypsin inhibitor (Type 1-S. Sigma Chemical Co.) and 0.5\% BSA. The cell suspension was centrifuged again at room temperature. The precipitated cells were resuspended in an appropriate volume of KRB-G (5.08 $\mathrm{mM} \mathrm{Ca}^{2+}$ ) containing 0.1\% soybean trypsin inhibitor and $0.5 \% \mathrm{BSA}$ and filtered again. The resuspended cells were preincubated at $35^{\circ} \mathrm{C}$ for $30 \mathrm{~min}$. The preincubated cell suspension was used for the experiment. All procedures were carried out in plastic tubes and siliconized glass ware and pipettes.

ACTH bioassay: The dried sample and standard $\mathrm{ACTH}_{1-24}$ were incubated with the isolated adrenal cell suspension by shaking at $37.5^{\circ} \mathrm{C}$ for $90 \mathrm{~min}$ under a gas phase of $5 \% \mathrm{CO}_{2}-95 \% \mathrm{O}_{2}$. The amount of produced corticosterone was measured fluorometrically by the method of Silber et al. (27) with the modification that $n$-hexane and sulfuric acid-ethanol $(7: 3, v / v)$ were used instead of isooctane and $30 \mathrm{~N}$ sulfuric acid, respectively. The amount of ACTH in the sample was calculated from the dose-response curve obtained with the standard $\mathrm{ACTH}_{1-24}$. Statistical analysis was performed by Student's $t$-test.

\section{Results}

The ACTH concentration in the serum of untreated rats $(n=23)$ was $10.0 \pm 0.7 \mathrm{pg} / \mathrm{ml}$ (mean \pm S.E.), and that at $10 \mathrm{~min}$ after the saline injection was $10.2 \pm 0.4 \mathrm{pg} / \mathrm{ml}$. Figure 2 shows the log dose-response relationships between doses of various adrenoceptor agonists and antagonists and the concentrations of ACTH in the rat serum. Ten minutes after the injection of various $\alpha$-adrenoceptor agonists, the ACTH concentration in the serum was increased dose-dependently. However, isoproterenol, a $\beta$-adrenoceptor agonist, had no effect on ACTH secretion at a dose of 0.05 to $0.4 \mathrm{mg} / \mathrm{kg}$. Large doses of $\alpha$-adrenoceptor antagonists, phentolamine, phenoxybenzamine, and yohimbine, greatly stimulated ACTH secretion by themselves. The log dose-response curves were used for calculating median effective dose (ED50) of various $\alpha$-adrenoceptor agonists on ACTH 
secretion. The order of ED50 was as follows: epinephrine $\because$ norepinephrine $<$ B-HT920 $<$ clonidine < phenylephrine $\ll$ B-HT933. Epinephrine and norepinephrine were about equally potent. B-HT933 was less effective than the other drugs (Table 1).

Figure 3 shows the time courses of the ACTH concentration in the serum after a single injection of phenylephrine (A) and clonidine (B). When $1.5 \mathrm{mg} / \mathrm{kg}$ of phenylephrine was injected, the ACTH concen- tration in the serum increased rapidly and reached its maximum level at $10 \mathrm{~min}$. Then it decreased, approaching the normal level at $60 \mathrm{~min}$. A similar time course was also observed with a single injection of $0.1 \mathrm{mg} / \mathrm{kg}$ of epinephrine (data not shown). The injection of $1.5 \mathrm{mg} / \mathrm{kg}$ of clonidine also produced a rapid increase in the serum $\mathrm{ACTH}$ level and a subsequent prolonged secretion of ACTH until $30 \mathrm{~min}$. The ACTH concentration then decreased gradually, but it was
(A) AGONISTS

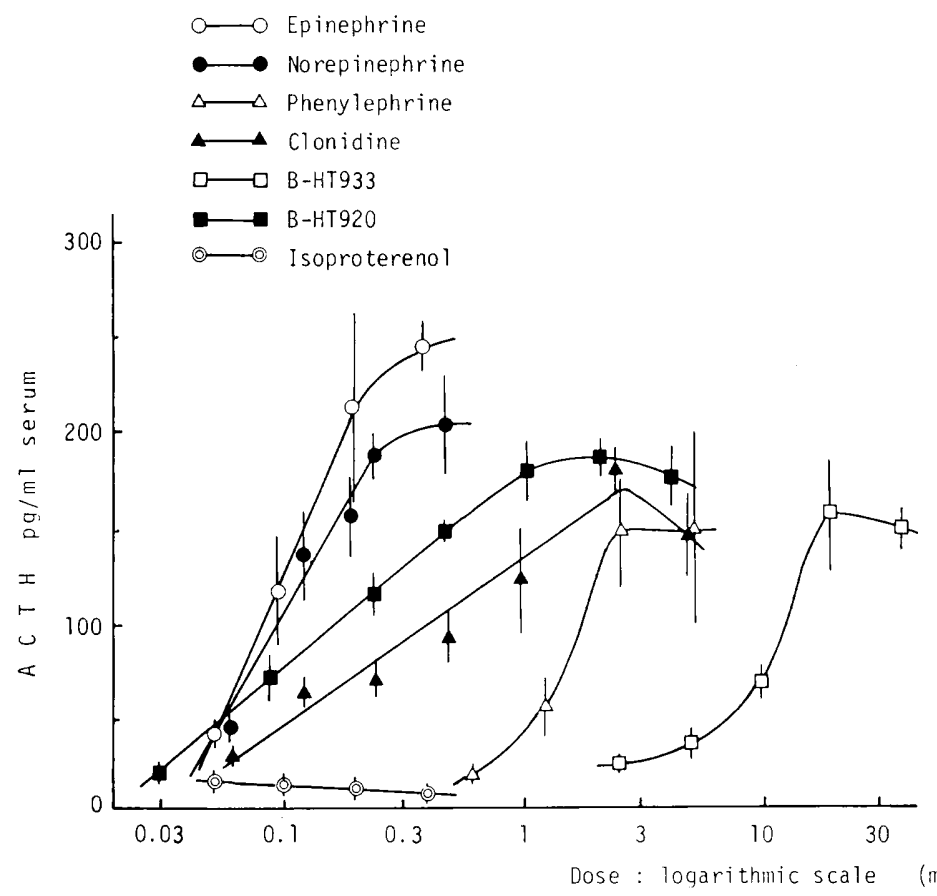

(B) ANTAGONISTS

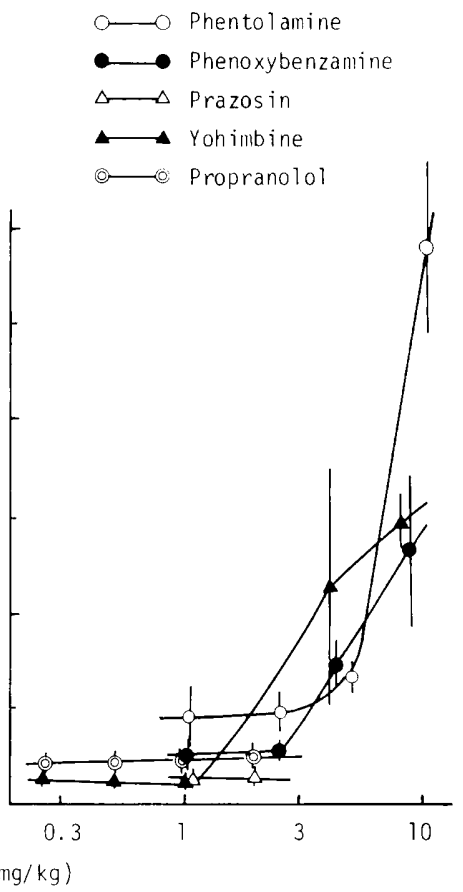

Fig. 2. Log dose-response curves of various adrenoceptor agonists $(A)$ and antagonists (B) on $A C T H$ secretion. Rats were decapitated $10 \mathrm{~min}$ after the injection of drugs. Each point shows the mean of 3 to 5 rats, and vertical bars represent the mean \pm S.E.

Table 1. ED50 (mg/kg i.p.) of various $\alpha$-adrenoceptor agonists on ACTH secretion

\begin{tabular}{lc}
\hline Drugs (agonists) & ED50 (mg/kg i.p.) \\
- & 0.10 \\
Epinephrine & 0.10 \\
Norepinephrine & 1.70 \\
Phenylephrine & 0.38 \\
Clonidine & 14.50 \\
B-HT933 & 0.16 \\
B-HT920 & 0 \\
\hline
\end{tabular}




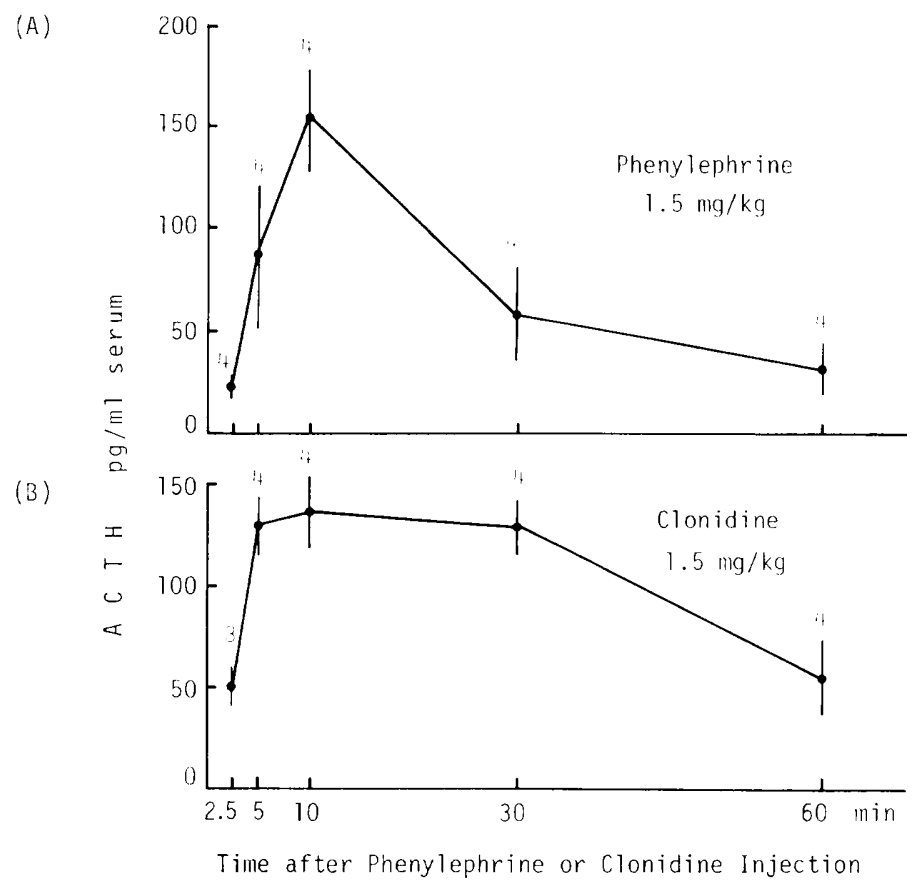

Fig. 3. Time courses of the ACTH concentration in the rat serum after a single injection of phenylephrine $(A)$ and clonidine $(B)$. The numbers above the bars are the number of rats and vertical bars represent the mean \pm S.E.
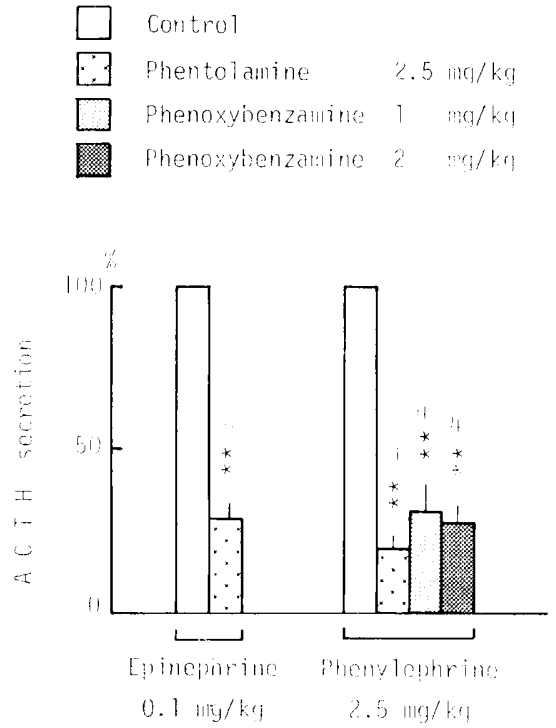

Fig. 4. Effect of pretreatment with phentolamine or phenoxybenzamine on ACTH secretion (\% of control) induced by epinephrine or phenylephrine. Pretreatment time of phentolamine and phenoxybenzamine was $5 \mathrm{~min}$ and $10 \mathrm{~min}$, respectively. Control responses were obtained from pretreatment with saline. Rats were decapitated $10 \mathrm{~min}$ after the injection of epinephrine or phenylephrine. The numbers above the bars are the number of rats, and vertical bars represent the mean \pm S.E. ${ }^{*} P<0.01$ : Significantly different from each control value. still at a relatively high level 60 min after the injection. Since the maximum concentration of ACTH was found at $10 \mathrm{~min}$ in these cases, rats were decapitated $10 \mathrm{~min}$ after the injection of adrenoceptor agonists throughout the experiments.

Figure 4 shows the effect of pretreatment with $\alpha$-adrenoceptor antagonists, phentol- 
amine and phenoxybenzamine, on ACTH secretion induced by epinephrine or phenylephrine. ACTH secretion induced by epinephrine was significantly inhibited by phentolamine $(2.5 \mathrm{mg} / \mathrm{kg})$. Phenylephrineinduced ACTH secretion was also significantly blocked both by phentolamine $(2.5 \mathrm{mg} / \mathrm{kg}$ ) and by phenoxybenzamine (1 or $2 \mathrm{mg} / \mathrm{kg}$ ). However, propranolol $(0.5$ to $2 \mathrm{mg} / \mathrm{kg})$, a $\beta$-adrenoceptor antagonist, did not inhibit ACTH secretion induced by $0.1 \mathrm{mg} / \mathrm{kg}$ of epinephrine (data not shown). In Fig. 4, the dose of each agonist was so chosen that it produces about $100 \mathrm{pg} / \mathrm{ml}$ of ACTH secretion. However, we could not obtain constantly $100 \mathrm{pg} / \mathrm{ml}$ of ACTH secretion for each agonist because individual rats had a different sensitivity to the drug. Then we repeated the experiment several times with the same dose for each agonist. In order to summarize the results, the effect of agonist after the injection of antagonist was shown as a percentage of the control. In later experiments, the results were also shown as a percentage of the control.
Figures 5 and 6 show the effect of pretreatment with prazosin, an $\alpha_{1}$-antagonist, or yohimbine, an $\alpha_{2}$-antagonist, on ACTH secretion induced by phenylephrine, norepinephrine, B-HT933, or clonidine. Prazosin $(0.5$ to $2 \mathrm{mg} / \mathrm{kg}$ ) significantly antagonized ACTH secretion induced by phenylephrine, but yohimbine $(0.5$ or $1 \mathrm{mg} / \mathrm{kg})$ had no statistically significant effect on the ACTH secretion induced by it. Norepinephrineinduced ACTH secretion was markedly blocked both by prazosin (1 or $2 \mathrm{mg} / \mathrm{kg}$ ) and yohimbine $(0.5 \mathrm{mg} / \mathrm{kg})$. B-HT933induced ACTH secretion was significantly inhibited by yohimbine $(0.25$ to $2 \mathrm{mg} / \mathrm{kg})$. but it was not inhibited by prazosin $(0.5$ to $2 \mathrm{mg} / \mathrm{kg}$ ). A similar result was also obtained with $20 \mathrm{mg} / \mathrm{kg}$ of B-HT933. ACTH secretion induced by $0.5 \mathrm{mg} / \mathrm{kg}$ of clonidine was significantly blocked both by prazosin (2 $\mathrm{mg} / \mathrm{kg})$ and by yohimbine $(0.5$ to 2 $\mathrm{mg} / \mathrm{kg}$ ), but that induced by $1 \mathrm{mg} / \mathrm{kg}$ of clonidine was inhibited only by prazosin. When $0.25 \mathrm{mg} / \mathrm{kg}$ of clonidine was injected, yohimbine was more effective than prazosin.
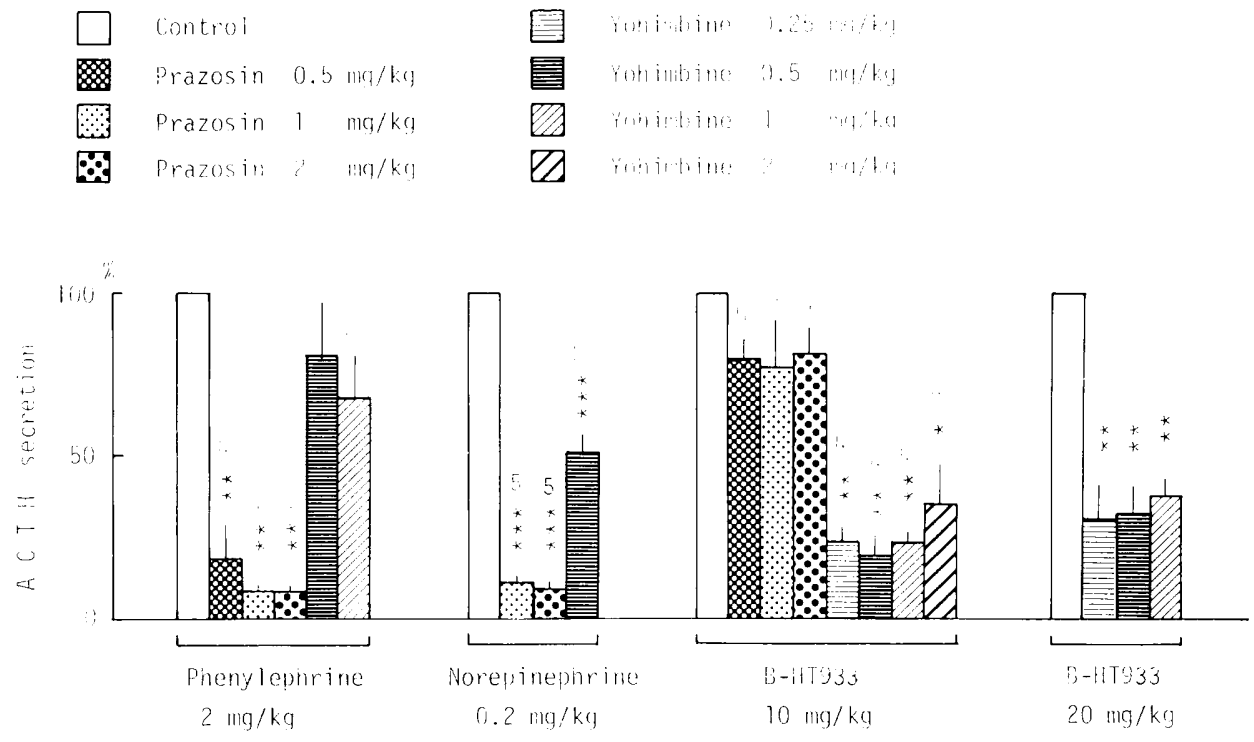

Fig. 5. Effect of pretreatment with prazosin or yohimbine on ACTH secretion (\% of control) induced by phenylephrine, norepinephrine, or B-HT933. Pretreatment time of prazosin and yohimbine was 30 min and $10 \mathrm{~min}$, respectively. Control responses were obtained from pretreatment with vehicle or saline. Rats were decapitated $10 \mathrm{~min}$ after the injection of phenylephrine, norepinephrine, or B-HT933. The numbers above the bars are the number of rats, and vertical bars represent the mean $\pm S . E .{ }^{*} P<0.05$, ${ }^{* *} P<0.01,{ }^{* *} P<0.001$ : Significantly different from each control value. 


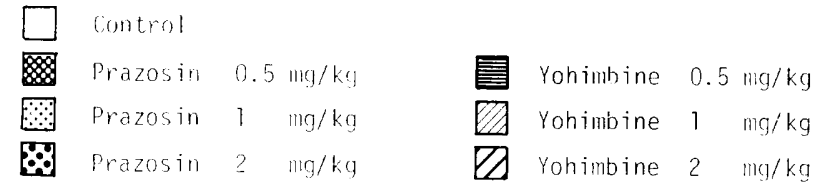

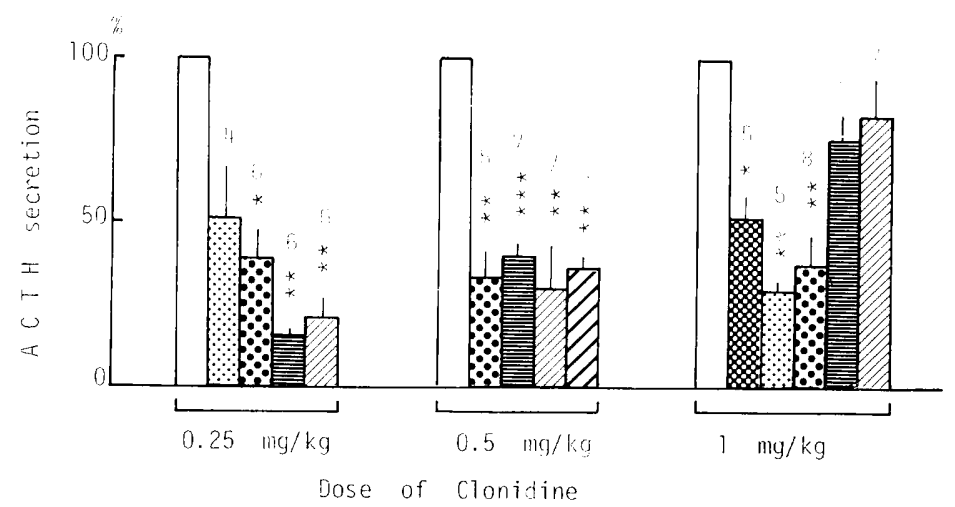

Fig. 6. Effect of pretreatment with prazosin or yohimbine on ACTH secretion (\% of control) induced by clonidine. Pretreatment time of prazosin and yohimbine was $30 \mathrm{~min}$ and $10 \mathrm{~min}$, respectively. Control responses were obtained from pretreatment with vehicle or saline. Rats were decapitated 10 min after the injection of clonidine. The numbers above the bars are the number of rats, and vertical bars represent the mean \pm S.E. ${ }^{*} \mathrm{P}<0.05,{ }^{*} \mathrm{P}<0.01,{ }^{* *} \mathrm{P}<0.001$ : Significantly different from each control value.
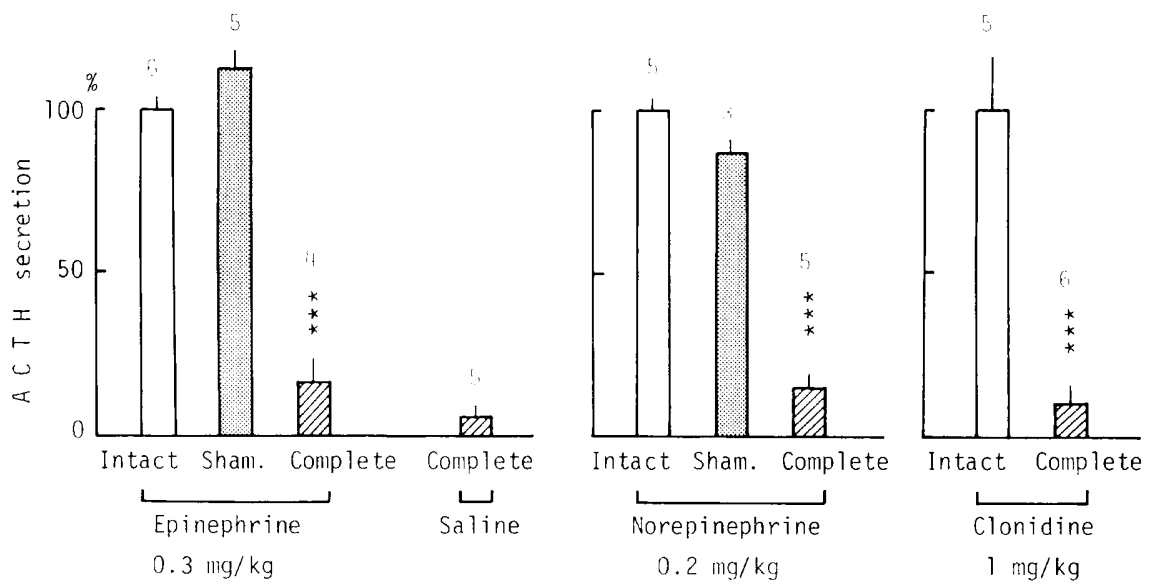

Fig. 7. Effect of complete hypothalamic deafferentation on ACTH secretion (\% of intact) induced by epinephrine, norepinephrine or clonidine. The drug was injected 5 to 6 days after hypothalamic deafferentation. Rats were decapitated $10 \mathrm{~min}$ after the injection of the drug. The numbers above the bars are the number of rats and vertical bars represent the mean $\pm S$.E. ${ }^{* * *} P<0.001$ : Significantly different from each intact value.

The effect of complete hypothalamic deafferentation on ACTH secretion is shown in Fig. 7. Epinephrine and norepinephrine produced $\mathrm{ACTH}$ secretion in sham-operated rats similar to that in intact rats. In deafferentated rats, injection of epinephrine $(0.3 \mathrm{mg} /$ $\mathrm{kg})$, norepinephrine $(0.2 \mathrm{mg} / \mathrm{kg})$, and clonidine $(1 \mathrm{mg} / \mathrm{kg})$ did not increase the 
ACTH concentration in the serum: ACTH secretion induced by these drugs was markedly inhibited by hypothalamic deafferentation. In deafferentated rats, the ACTH concentration in the serum at $10 \mathrm{~min}$ after the saline injection was $10.0 \pm 4.1 \mathrm{pg} / \mathrm{ml}$, and that at $10 \mathrm{~min}$ after the epinephrine injection was $22.3 \pm 8.2 \mathrm{pg} / \mathrm{ml}$. A significant difference between these results could not be observed, but the ACTH concentration in the serum after epinephrine injection was always higher than that after saline injection.

\section{Discussion}

In this paper it was confirmed that when various adrenergic drugs are systemically injected, $\alpha$-adrenoceptors are mainly responsible for ACTH secretion and $\beta$ adrenoceptors are not important for it. However, there are some reports that $\mathrm{ACTH}$ secretion is mediated by $\beta$-adrenoceptors ( 10 . 11). Their experimental conditions are different from our conditions. Tilders et al. (10) infused drugs into a lateral tail vein of female Wistar rats under anesthesia. The influence of anesthesia on ACTH secretion and the difference in strain can not be disregarded. Fahringer et al. (11) used a higher dose of phentolamine. As will be discussed later, higher doses of $\alpha$-adrenoceptor antagonists produced ACTH secretion by themselves. As previously mentioned, $\alpha$-adrenoceptors have been subclassified pharmacologically into $\alpha_{1}$ - and $\alpha_{2}$ adrenoceptors $(12,13), \alpha_{1}$-Adrenoceptor was preferentially stimulated by phenylephrine and metoxamine, and it was inhibited by prazosin. $\alpha_{2}$-Adrenoceptor was preferentially stimulated by guanabenz and clonidine, and it was blocked by rauwolscine and yohimbine. In the present experiments, ACTH secretion induced by phenylephrine was completely blocked by prazosin (Fig. 5), and yohimbine inhibited significantly ACTH secretion induced by a low dose of clonidine (Fig. 6) and B-HT933 (Fig. 5). These results suggest that both $\alpha_{1}$ - and $\alpha_{2}$-adrenoceptors are involved in ACTH secretion induced by adrenergic drugs in rats.

Clonidine is generally accepted as an $\alpha_{2}-$ adrenoceptor agonist. In the present experiment (Fig. 6), ACTH secretion induced by a low dose of clonidine was effectively blocked by yohimbine, while that induced by a high dose of clonidine was blocked only by prazosin. In pithed rats. Timmermans et al. (14) reported similar results that vasopressor responses induced by a low dose of clonidine are blocked only by yohimbine, but those induced by a relatively high dose of clonidine are markedly inhibited by prazosin. Therefore, it is reasonable to assume that clonidine has a higher affinity for the $\alpha_{2}$-adrenoceptor than for the $\alpha_{1}$-adrenoceptor: Low doses of clonidine stimulate mainly $\alpha_{2}$-adrenoceptor, while high doses of clonidine stimulate $\alpha_{1}$ adrenoceptor in addition to $\alpha_{2}$-adrenoceptor.

Some of the $\alpha$-adrenoceptor antagonists, phentolamine, phenoxybenzamine and yohimbine, caused a great stimulation of ACTH secretion by themselves at higher doses (Fig. 2). A similar result has been observed by Ohler and Sevy (7) that dibenamine, an $\alpha$-adrenoceptor antagonist, itself produces an acute reduction in adrenal ascorbic acid. These results suggest that higher doses of $\alpha$-adrenoceptor antagonist themselves may have the property of an $\alpha$ adrenoceptor agonist, or they may involve factors other than an $\alpha$-adrenergic blockade. High doses of various $\alpha$-adrenoceptor blocking drugs have been reported to produce pressor responses in dogs (28) and cats $(29,30)$, which are the remarkable effects of various $\alpha$-adrenergic agonists.

It is well known that ACTH secretion is increased by various stresses. Fortier has divided ACTH-releasing stressful stimuli into two functionally distinct classes: neural and systemic stimuli (19). Neural stimuli may provide signals for the secretion of corticotropin-releasing factor (CRF) through afferent pathways to the hypothalamic median eminence. Neural afferent pathways are not essential for systemic stimuli. In systemic stimuli, ACTH-releasing neurohumor distinct from CRF, passes by the systemic blood stream directly to the pituitary gland, effecting ACTH release. Therefore, some explanations may be given for ACTH secretion induced by the systemic injection of various adrenergic drugs. The first possibility is the neural passway mediated by the nervous system. Various systemically injected 
adrenergic drugs act directly on sympathetic effector cells following interaction with peripheral $\alpha$-adrenoceptors. These drugs exert an influence upon biochemical reactions and functional responses in all tissues. These responses induced by stimulation of $\alpha$ adrenoceptors may become the stressor for neural stimuli which produces ACTH secretion. One of the most striking effects of many adrenergic stimulating drugs is that they increase arterial blood pressure due to stimulation of $\alpha$-adrenoceptors in the vascular system. It seems likely that pressor responses produce strong stresses and yield ACTH release. Up to now, it has not been reported that pressor responses produce ACTH secretion, while there are some reports (7. 31 ) that ACTH secretion induced by epinephrine is not mediated through the pressor effect. However, the possible role of cardiovascular effects on ACTH secretion cannot be excluded. In the present experiment, trunk blood volume was decreased dosedependently after clonidine injection. This decrease of the blood volume seems to be due to vasodilation. Clonidine produces some direct peripheral vasodilation (32). Prazosin and yohimbine inhibited both the decrease of the blood volume and the increase of ACTH secretion induced by clonidine. An inverse correlation was found between the blood volume and ACTH secretion (data not shown). In the previous experiment (33). after histamine injection, trunk blood volume was markedly decreased, and this decrease in the blood volume was inhibited by antihistaminic drugs. ACTH concentration in the serum was also increased after histamine injection and this increase was inhibited by antihistaminic drugs. It is generally known that hypotension which arises from hemorrhage causes activation of the pituitaryadrenal system in animals (34-37). Furthermore Gann et al. $(38,39)$ and Wood et al. $(40,41)$ have reported that adrenal cortical response to hypotension may be mediated in part by vagal pathways and by carotid baroreceptors. Therefore, these results suggest that the decrease of the circulating blood volume is closely related to the stimulation of ACTH secretion. Changes in blood pressure or blood flow in the periphery which are induced by various adrenergic stimulating drugs may become the stressors and may act as the trigger signals for ACTH secretion. The second possibility is the systemic passway. Epinephrine and norepinephrine cannot easily pass the blood-brain barrier. However, the direct action of these drugs on the median eminence and pituitary gland should not be disregarded because these areas are located outside the barrier. It was shown by Weil Malherbe et al. (42) that 2 min after a rapid intravenous injection, the pituitary gland contained radioactive norepinephrine in high concentration, exceeding that in plasma. Direct action of epinephrine and norepinephrine in anterior pituitary cells in primary culture was also reported by Giguère et al. $(43,44)$. In the present experiment, ACTH secretion induced by epinephrine was markedly inhibited by complete cuts around the $\mathrm{MBH}$. In deafferentated rats, however, the ACTH concentration in the serum after epinephrine injection tended to be at a higher concentration than that after saline injection, although it was not significantly higher. This may be due to the contribution from the direct action on the pituitary gland or median eminence.

From these results, it is concluded that ACTH secretion induced by systemically injected adrenergic drugs in rats is mediated via both $\alpha_{1}$ - and $\alpha_{2}$-adrenoceptors, and intact neural pathways entering the $\mathrm{MBH}$ are necessary for the $\mathrm{ACTH}$ releasing action. However, the direct action on pituitary gland or median eminence can not be excluded. It may be partly involved in ACTH secretion induced by these drugs.

Acknowledgements: I would like to express my sincere thanks to Dr. Y. Morita for her advice and encouragement throughout this study. I wish to thank Nippon Boehringer-Ingelheim. Ltd. for the gifts of B-HT933 and B-HT920 and Pfizer Taito, Ltd. for the gift of prazosin.

\section{References}

1 Vogt, M.: Observations on some conditions affecting the rate of hormone output by the suprarenal cortex. J. Physiol. (Lond.) 103, $317-$ 332 (1944)

2 Long, C.N.H. and Fry, E.G.: Effect of epinephrine on adrenal cholesterol and ascorbic acid. Proc. Soc. Exp. Biol. Med. 59, 67-68 (1945) 
3 Sayers, G. and Sayers, M.A.: Regulation of pituitary adrenocorticotrophic activity during the response of the rat to acute stress. Endocrinology 40, 265-273 (1947)

4 Smelik, P.G. and de Wied, D.: Corticotrophinreleasing action of adrenaline, serotonin and pitressin. Experientia 14, 17 (1958)

5 Smelik, P.G.: Mechanism of hypophysial response to psychic stress. Acta Endocrinol. 33, 437-443 (1960)

6 Vernikos-Danellis, J. and Marks, B.H.: Epinephrine-induced release of $\mathrm{ACTH}$ in normal human sujects: a test of pituitary function. Endocrinology 70, 525-531 (1962)

7 Ohler, E.A. and Sevy, R.W.: Effect of pressor amines and adrenergic blockade on adrenal ascorbic acid concentration in rats. Am. J. Physiol. 175, 285-288 (1953)

8 Siderius, P. and Gaarenstroom, J.H.: The effect of dihydroergotamine on the blood count and adrenal cortical response to adrenaline. Acta Endocrinol. 9, 109-117 (1952)

9 Nakai, Y., Imura, H., Yoshimi, T. and Matsukura, S.: Adrenergic control mechanism for ACTH secretion in man. Acta Endocrinol. 74, 263-270 (1973)

10 Tilders, F.J.H., Berkenbosch, F. and Smelik, P.G.: Adrenergic mechanisms involved in the control of pituitary-adrenal activity in the rat: a $\beta$ adrenergic stimulatory mechanism. Endocrinology 110, 114-120 (1982)

11 Fahringer, E.E., Foley, E.L. and Redgate, E.S.: Pituitary adrenal response to ketamine and the inhibition of the response by catecholaminergic blockade. Neuroendocrinology 14 151-164 (1974)

12 Starke, K. and Langer, S.Z.: A note on terminology for presynaptic receptors. In Presynaptic Receptors, Advances in the Biosciences, Edited by Langer, S.Z., Starke, K., and Dubocovich, M.L., Vol. 18, p. 1-3, Pergamon Press, Oxford (1979)

13 Langer, S.Z.: Presynaptic regulation of the release of catecholamines. Pharmacol. Rev. 32, 337-362 (1980)

14 Timmermans, P.B.M.W.M. and van Zwieten, P.A.: Postsynaptic $\alpha_{1}$ - and $\alpha_{2}$-adrenoceptors in the circulatory system of the pithed rat: selective stimulation of the $\alpha_{2}$-type by B-HT933. Eur. J. Pharmacol. 63, 199-202 (1980)

15 Kobinger, W. and Pichler, L.: Investigation into different types of post- and presynaptic $\alpha$ adrenoceptors at cardiovascular sites in rats. Eur. J. Pharmacol. 65, 393-402 (1980)

16 Timmermans, P.B.M.W.M. and van Zwieten, P.A.: Vasoconstriction mediated by postsynaptic $\alpha_{2^{-}}$ adrenoceptor stimulation. Naunyn Schmiedebergs Arch. Pharmacol. 313, 17-20 (1980)

17 van Meel, J.C.A., Timmermans, P.B.M.W.M. and van Zwieten, P.A.: Selectivity of some agonists for postsynaptic $\alpha_{1}$ - and $\alpha_{2}$-adrenoceptors in the vascular system of the pithed rat. Naunyn Schmiedebergs Arch. Pharmacol. Supp. 313, R22 (1980)

18 Pichler, L.: Determination of $\alpha_{1} / \alpha_{2}$ specificity for various $\alpha$-adrenoceptor agonists. Naunyn Schmiedebergs Arch. Pharmacol. Supp. 316. R56 (1981)

19 Fortier, C.: Dual control of adrenocorticotrophin release. Endocrinology 49, 782-788 (1951)

20 Fortier, C. and Selye, H.: Adrenocorticotrophic effect of stress after severance of the hypothalamo-hypophyseal pathways. Am. J. Physiol. 159, 433-439 (1949)

21 Makara, G.B., Stark, E. and Palkovits, M.: Afferent pathways of stressful stimuli: Corticotrophin release after hypothalamic deafferentation. J. Endocrinol. 47, 411-416 (1970)

22 Kárteszi, M., Makara, G.B. and Stark, E.: The rise of plasma ACTH induced by ether is mediated through neural pathways entering the medial basal hypothalamus. Acta Endocrinol. 93, 129133 (1980)

23 Makara, G.B., Stark, E., Kárteszi, M., Fellinger, E., Rappay, G. and Szabó, D.: Effect of electrical stimulation of the neurohypophysis on ACTH release in rats with hypothalamic lesions. Neuroendocrinology 31, 237-243 (1980)

24 Halász, B. and Pupp, L.: Hormone secretion of the anterior pituitary gland after physical interruption of all nervous pathways to the hypophysiotrophic area. Endocrinology 77, 553-562 (1965)

25 Morita, Y. and Koyama, K.: ACTH bioassay using isolated adrenal cells and its application to determination of serum and pituitary ACTH levels in morphine-injected rats. Endocrinol. Japon. 24, 317-326 (1977)

26 Sayers, G., Swallow, R.L. and Giordano, N.D.: An improved technique for the preparation of isolated rat adrenal cells: A sensitive, accurate and specific method for the assay of ACTH. Endocrinology 88, 1063-1068 (1971)

27 Silber, R.H., Busch, R.D. and Oslapas, R.: Practical procedure for estimation of corticosterone or hydrocortsone. Clin. Chem. 4, 278285 (1958)

28 Benfey, B.G.: Cardiovascular actions of phenoxybenzamine. Br. J. Pharmacol. 16, 6-14 (1961)

29 Benfey, B.G. and Varma, D.R.: Studies on the cardiovascular actions of antisympathomimetic 
drugs. Int. J. Neuropharmacol. 1, 9-12 (1962)

30 Drew, G.M. and Whiting, S.B.: Evidence for two distinct types of postsynaptic $\alpha$-adrenoceptor in vascular smooth muscle in vivo. Br. J. Pharmacol. 67, 207-215 (1979)

31 Ronzoni, E. and Reichlin, S.: Adrenergic agents and the adrenocorticotrophic activity of the anterior pituitary. Am. J. Physiol. 160, 490-498 (1950)

32 Shaw, J., Hunyor, S.N. and Korner, P.I.: The peripheral circulatory effects of clonidine and their role in the production of arterial hypotension. Eur. J. Pharmacol. 14, 101-111 (1971)

33 Morita, Y. and Koyama, K.: Studies on histamineinduced ACTH secretion. Japan. J. Pharmacol. Supp. 26, 127P (1976)

34 Sayers, G., Sayers, M.A., Liang, T. and Long, C.N.H.: The cholesterol and ascorbic acid content of the adrenal, liver, brain, and plasma following hemorrhage. Endocrinology 37, 96-110 (1945)

35 Atkins, G. and Marotta, S.F.: Relationship of altered vascular volumes to plasma 17-hydroxycorticosteroids in dogs. Proc. Soc. Exp. Biol. Med. $113,461-465$ (1963)

36 Gann, D.S. and Egdahl, R.H.: Responses of adrenal corticosteroid secretion to hypotension and hypovolemia. J. Clin. Invest. 44, 1-7 (1965)

37 Redgate, E.S.: Role of the baroreceptor reflexes and vasoactive polypeptides in the corticotropin release evoked by hypotension. Endocrinology
82, 704-720 (1968)

38 Gann, D.S., Lance-Gould, K., Morley, J.E. and Mumma, J.V.: Effects of vagotomy and of carotid constriction on corticosteroid secretion in the dog. Proc. Soc. Exp. Biol. Med. 115, 944-947 (1964)

39 Gann, D.S.: Carotid vascular receptors and control of adrenal corticosteroid secretion. Am. J. Physiol. 211, 193-197 (1966)

40 Wood, C.E., Keil, L.C. and Rudolph, A.M.: Hormonal and hemodynamic responses to vena caval obstruction in fetal sheep. Am. J. Physiol. 243, E278-E286 (1982)

41 Wood, C.E. and Rudolph, A.M.: Carotid vascular control of ACTH secretion in lambs. Am. J. Physiol. 244, E555-E559 (1983)

42 Weil- Malherbe, H., Whitby, L.G. and Axelrod, J.: The uptake of circulating ${ }^{3} \mathrm{H}$-norepinephrine by the pituitary gland and various areas of the brain. J. Neurochem. 8, 55-64.(1961)

43 Giguère, V., Cote, J. and Labrie, F.: Characteristics of the $\alpha$-adrenergic stimulation of adrenocorticotropin secretion in rat anterior pituitary cells. Endocrinology 109, 757-762 (1981)

44 Giguère, V. and Labrie, F.: Additive effects of epinephrine and corticotropin-releasing factor (CRF) on adrenocorticotropin release in rat anterior pituitary cells. Biochem. Biophys. Res. Commun. 110, 456-462 (1983) 